\title{
An Analysis of the Advantages and Disadvantages of Large Class Enrollment in Chinese Universities
}

\author{
Li Yixiao \\ Student of School of Humanity and Law, Northeastern \\ University \\ ShenYang, China
}

\author{
Yao Tianchong \\ Adjunct professor of School of Humanity and Law, \\ Northeastern University \\ Shen Yang, China
}

\begin{abstract}
Large class enrollment in Chinese Universities is a kind of talent cultivation mode for students. After $1 \sim 2$ years of public basic course training, then the subjects are divided according to interests and scores. Large class enrollment in Chinese Universities is inevitable requirement of the times and social development. Only a wide range of high-quality college students can solve our country current talent dilemma. However, it still have some disadvantages, for example, students lack effective professional guidance, students' enthusiasm for learning is frustrated and there is imbalance in professional development of popular and unpopular. This paper makes a detailed analysis from historical reasons and historical background, advantages and disadvantages of large class enrollment in Chinese Universities. Our conclusion is that although there are some deficiencies in large class enrollment in Chinese Universities, it has potential and vitality. We are aimed at providing some theoretical references for it.
\end{abstract}

Keywords-Large class enrollment in Chinese Universities; Analysis of advantages and disadvantages; Professional shunt; Cultivation of talents

\section{INTRODUCTION}

As a new thing, Large class enrollment in Chinese Universities needs to be tested in practice. Only have a clear understanding of college, can we Identify problems and solve them. If colleges can establish a scientific and effective guidance mode, Large class enrollment in Chinese Universities will have a broader development space.

\section{HISTORICAL BACKGROUND FOR LARGE CLASS ENROLLMENT IN CHINESE UNIVERSITIES}

It is an inevitable requirement of the times and social development to carry out the Large class enrollment in Chinese Universities. After entering the 21st century, global economic integration is becoming more and more obvious, the speed of knowledge update also significantly accelerated and subjects' boundaries are broken gradually [1]. It is necessary for high education to cultivate talents who have broad knowledge and solid foundation. Talent selection and training mode are closely related to the quality of talent cultivation, so establishing a new talent cultivation mode has become the top issue of education reform and development. At present, the main disadvantages of education in our current undergraduate courses are single knowledge structure, weak quality education and narrowness of the basic knowledge. This has not met the demand of the modern society for the knowledgeable, adaptable, thoughtful and innovative talents. The long-term education practice in China also proves that students early entering into professional study leads to a narrow range of knowledge, which make a lack of science knowledge in student of liberal arts, and a lack of humanistic knowledge in student majored in science. Experienced university presidents know unless countries desperately need some special talents, professional settings are commonly should not be too narrow. They must consider avoid new talents soon face with employment difficult deformity.

In practice, colleges in China have found that it is not conducive to satisfy the demands of university personnel training.

Recruitment of students scale is relatively stable in colleges, the total number of admissions are just several thousand. In terms of professional recruitment of students, every year dozens or even hundreds of professions enrolling new students, average per major just has fewer than 100 people, and then assigned to the provinces, a lot of professional in a province only recruit one or two people. It is difficult for high school student to choose. Colleges are also easy to lose good candidates.

For this reason, many colleges try to break the barrier of the professional, establishing in the undergraduate education with quality education as the orientation of the interdisciplinary system. They desire to let students dabble in different subject areas and broaden the knowledge base, so they can become qualified talents in the 21 st century.

\section{THE ADVANTAGES AND DISADVANTAGES OF LARGE CLASS ENROLLMENT IN CHINESE UNIVERSITIES}

Like taiji diagram, everything has advantages and disadvantages. Large class enrollment in Chinese Universities as a unique and new mode, not only has its positive side, but also has its negative side.

What we need to do is to make an analysis of Large class enrollment in Chinese Universities, with a view to adopt its good points and avoid its shortcomings. 


\section{A. The advantages of Large class enrollment in Chinese Universities}

Large class enrollment in Chinese Universities' is the demand of practice, which has necessity of surviving. Understanding Large class enrollment in Chinese Universities' benefits is helpful to know how important Large class enrollment in Chinese Universities is [3].

\section{1) Effectively avoid the blindness of students to fill out college application}

Students Fill out college application mostly affected by the social climate and the employment situation. In many colleges, the number of candidate are often imbalanced. Students enter some popular majors intensively, but popular majors tend to score higher, which has caused many students cannot reach the popular major scores .Some majors have a certain market demand, but due to lack of popularity, many students are unwilling to fill in the paper, which is a great waste to the discipline construction and education resources of colleges [2]. Colleges adopt a broad class enrollment model can effectively solve the problem of university professional settings and educational resource optimization. On the one hand, Large class enrollment in Chinese Universities is associated with many majors with different angles and coverage. Therefore, the demand for talents is more obvious, which can directly reduce the risk of failing. More important, Large class enrollment in Chinese Universities can provide students with more opportunities to choose, and improve the chances of being admitted, so as to attract more excellent students. On the other hand, in the later stage of talent cultivation, students can have more space to choose major, which can effectively avoid the mistakes misunderstanding major then choose wrong. It is conducive to the consolidation and stability of the students' thought.

\section{2) Large class enrollment in Chinese Universities is the need for the development of education}

According to the actual needs, modern society needs people with more knowledge and adaptability. Higher education should not only train students' professional skills, but also cultivate students' ability to master the knowledge of different subjects. The practice proves that the simple mastery of a professional knowledge is far from enough to meet the needs of work. During the study period, university students need to widen their knowledge and not be limited by their major. College students should actively explore the methods of solving problems and thinking activities in different subjects, so as to make a difference. To master different professional knowledge is not to set them against each other, but to try to find common ground between different subjects and to learn more about major. Only in this way can they find better work in society and learn new knowledge more quickly .Large class enrollment in Chinese Universities is adapted to the needs of the market economy and the diversity of social life. It helps to solve the current shortage of comprehensive talents.

\section{3) Large class enrollment in Chinese Universities is conducive to cultivating creative talents}

To build an innovation-oriented country and take the development path of independent innovation, we will require colleges to train complex and innovative talents. Therefore, as the basic stage of talent cultivation, the undergraduate stage should be transformed from professional education to wide caliber talents training mode. Large class enrollment in Chinese Universities can help students to get a wide - caliber and basic training after entering, thus avoiding the disadvantages of narrow knowledge and lack of basic quality due to the early entry of professional study.

At the same time, after a year of study, students' ability to learn independently is improved, which is conducive to the individualized development of students and the cultivation of innovative talents.

\section{B. The disadvantages of Large class enrollment in Chinese Universities}

There are no perfect things in the world, Large class enrollment in Chinese Universities also has many problems. But that doesn't make it a reason to give up college classes. We need to take a dialectical view of college students' enrollment pattern, find problems and solve problems.

\section{1) Students lack effective professional guidance}

First of all, it weakens the professional basic course education. The complete discipline is the basic requirement of Large class enrollment. The mode of "Enrolment and training of students in large category", strengthens the foundation education and enhances the students' adaptability .But at the same time, because students are not studying their own majors in their first year, they are not divided into same discipline. Therefore, it becomes particularly difficult for making the plan of talent training, relevant professional courses have to be delayed. And lectures and classes are forced to scale back. This will weaken the professionalism of college talent cultivation.

Secondly, due to the professional uncertainty, students have no definite plans for the future development. Fresh year is a time for students to determine their major and interest. During this period, the student's goal is not clear. Even with clear goals, students don't know what they need to prepare for their professional studies because they don't have a professional teacher to teach them. It can be said that the students spent the whole academic year in hesitation and confusion. We have to say it's a waste of time [4].

\section{2) Students' enthusiasm for learning is frustrated}

When students just enter university, because has not taken over the student work, is in the most high learning enthusiasm and the most energetic time. However, a common course is not often associated with later professional course too much, which hit the enthusiasm of students learning, at the same time, also directly affects the grades. For example, a student, who enter the university using Large class enrollment mode, but common courses founded by school has nothing to do with the law, such as advanced mathematics, university physics, he may loses interest in learning. This leads to the student's grade 
point is very low. However, in the time of professional diversion, grade point is an important reference for choosing a major. The student, who is dream to learn law, may not be able to achieve it. It is contrary to the original intention of Large class enrollment in Chinese Universities [5]. As a new personnel training mode, Large class enrollment in Chinese Universities aims to enable students to pass a year to really understand their favorite professional, so as to improve the enthusiasm of learning, rather than reduce the students' interest in learning. However, if the school cannot reasonably arrange the students' courses and improve the students' interest in the major, things can go wrong.

\section{3) There is imbalance in professional development of popular and unpopular}

After the students enter the university, they will continue to study the public courses. But there are few schools can carry out scientific professional conduct .This results in the students are not familiar with their major and career prospects. After all, students' experience and experience are limited. In the absence of scientific professional conduct, students can only choose according to their own understanding. There may be a large number of students blindly choosing the same major, while some majors are unselected [6]. This phenomenon has created so-called popular majors and unpopular majors, which artificially exacerbate the polarization of the profession. Moreover, this phenomenon also leads to the waste of teaching resources, which is also detrimental to the development of school teaching. It can be imagined that, in this situation, the mode of Large class enrollment in Chinese Universities can not only play their due role, but also increase the blindness of students' choice of majors.

\section{THE AdVICE OF SOlVING PROBlems OF LARGE Class ENROLLMENT IN CHINESE UNIVERSITIES}

The above problem is not an accidental phenomenon, but a result of a variety of factors. The problems not only existing in the education system of colleges but also are inseparable from the overall social needs. Therefore, to solve these problems, it is necessary for the whole society to work together. The author believes that we can start from the following aspects.

(1)The school should be fully aware of its own conditions, and according to the actual situation of the school, we should carefully implement the training of students according to the professions, and reasonably set the enrollment caliber. The division of the training category should be in the interest of the students, and the students, teaching and teachers should be considered in a comprehensive way. Only in this way can the quality and professional development prospects be affected. Improve the teaching quality security system and the system construction, improve the teachers' teaching quality evaluation mechanism, incentive mechanism of teaching achievements, mobilize the enthusiasm and initiative of teachers in teaching, unceasingly promote the personnel training quality.
(2)The school should strengthen students' professional education, so that students can fully understand the professional characteristics of this subject. To provide students with professional guidance that is in line with their interests and their interests. The school can organize teachers of high level of disciplines to hold a lecture or organize the students from the upper classes and freshmen to exchange meetings. Only in this way can the students of each major reach the basic balance of the professional number, and the students can choose the satisfactory major.

(3)Colleges should reasonably allocate resources of education. It is conducive to creating a fair, just and open competition environment and preferential admission. This needs to be fully investigated to maintain a relative balance between the majors in each category.

\section{CONCLUSION}

Large class enrollment in Chinese Universities as a new personnel training mode, has its own advantages and limitations. But in my opinion, if school can establish scientific and effective mechanism of professional guidance, Large class enrollment in Chinese Universities is successful. Universities that use large class enrollment mode, should set up public courses being related to specialized courses, lead students grasp some knowledge and skills, cultivating self-study ability, independent consciousness and the spirit of daring to question. After all, college is the last stop before students enter the society. It should not only teach knowledge but also the ability to use knowledge to solve problems. If the university can effectively solve the problems of professional guidance, Large class enrollment in Chinese Universities will naturally play a positive role and add a new way for the cultivation of talents.

\section{REFERENCES}

[1] FengKaifu.Colleges and universities press the cool thinking of enrollment,[A] Journal of China West Normal University,1.2011,(3).

[2] QianBaoli.The university adopts the optimization strategy of the major categories of enrollment,[J]Education comments,2.2015,(4).

[3] Wu Tiefeng,ZhaoZhiji.Based on the "core + directional" course system of the training methods of the broad categories of recruitment talents, the analysis is made,[A],China Management Informationization,(2017)13-0249-03.

[4] LiBin,LuoGanhong.College enrollment: a promotion mode of elite education,[A] Central South University(2012)05-0011-06.

[5] LuoXaotian.Major categories of enrollment: new trend of college enrollment,[A] Economic Research Guide,(2011)20-0256-02.

[6] ZhangXiaofen.The "new students guide" model for major categories of enrollment,[A]Journal of Shenyang Normal University (Natural Science), 2012.02.041. 